Revista Água Viva

ISSN 1678-7471

\title{
DO LIXO AO LIVRO: QUARTO DE DESPEJO E DIÁRIO DE BITITA, DE CAROLINA MARIA DE JESUS
}

\section{FROM THE TRASH TO THE BOOK: QUARTO DE DESPEJO AND DIÁRIO DE BITITA, BY CAROLINA MARIA DE JESUS}

Flavia de Castro Souza ${ }^{1}$

Recebido em: 14 abr. 2020.

Aceito em: 26 jul. 2020.

DOI 10.26512/aguaviva.v5i3.30886

\begin{abstract}
RESUMO: Carolina Maria de Jesus revela em Quarto de despejo (1960) e Diário de Bitita (1986) o cotidiano de muitas brasileiras negras do século XX. Da infância no interior de Minas Gerais à vida adulta na favela do Canindé, São Paulo, a trajetória de Carolina foi marcada pela rejeição ao tentar adentrar espaços marcados pelo privilégio branco. Os diários de Carolina podem ser considerados denúncias contra seus agressores, embora tragam, em sua forma, traços de uma cultura dominante assimilada. A escrita poética de Carolina é forjada na tentativa de emergir de uma camada subalterna à elite, revelando um deslocamento do ponto de vista de classe. Durante a ditadura militar no Brasil, sua obra passa a ser censurada e silenciada da cena literária porque sua crítica social não atendia o padrão proposto pelos militares. Analisarei as relações entre os sujeitos subalternizados e o sistema literário brasileiro, através da escrita íntima de Carolina.
\end{abstract}

Palavras-chave: Carolina Maria de Jesus. Sistema literário brasileiro. Feminismo. Relações raciais. Classe.

\begin{abstract}
Carolina Maria de Jesus reveals in Quarto de despejo (1960) and Diário de Bitita (1986) the daily life of many black Brazilian women of the twentieth century. From childhood in the inlands of Minas Gerais to adulthood in the Canindé slum, São Paulo, Carolina's trajectory was marked by rejection as she tried to enter spaces marked by white privilege. Carolina's diaries can be considered denunciations of her perpetrators, though they bear in their form traces of an assimilated dominant culture. Carolina's poetic writing is forged in an attempt to emerge from a subaltern layer to the elite, revealing a shift from the class point of view.

\footnotetext{
${ }^{1}$ Possui graduação em Letras (Licenciatura em Língua Portuguesa) pela Universidade Federal de Goiás (2006) e graduação em Letras (Bacharelado em Literatura e Língua Portuguesa) pela Universidade Federal de Goiás (2004). Concluiu o Mestrado em 2009, defendendo a dissertação intitulada "Trilogia da morte: o imaginário em Lygia Bojunga", na Faculdade de Letras também na Universidade Federal de Goiás, na área de concentração de Estudos Literários. Cursa atualmente o Doutorado em Literatura na Universidade de Brasília - PósLIT/UnB (2018-2021) com projeto na Linha de Pesquisa Representação na Literatura Contemporânea. E-mail: sapatosprateados@gmail.com
} 
During the military dictatorship in Brazil, her work became censored and silenced from the literary scene because its social criticism did not meet the standard proposed by the military. I will analyze the relationships between subordinate subjects and the Brazilian literary system through Carolina's intimate writing.

Keywords: Carolina Maria de Jesus. Brazilian literary system. Feminism. Race relations. Class.

\title{
TRILHANDO OS PRÓPRIOS CAMINHOS LITERÁRIOS
}

O primeiro romance escrito por uma mulher negra no Brasil de que temos notícia foi Úrsula, de Maria Firmina dos Reis, publicado em 1859. Em seu prólogo a autora maranhense faz um apelo aos possíveis leitores da obra para que a leiam, por dois motivos: para que assim tenha ânimo de continuar escrevendo e também para incentivar outras mulheres a se tornarem escritoras:

\begin{abstract}
Não a desprezeis [Úrsula], antes amparai-a nos seus incertos e titubeantes passos para assim dar alento à autora de seus dias, que talvez com essa proteção cultive mais o seu engenho, e venha a produzir coisa melhor, ou, quando menos, sirva esse bom acolhimento de incentivo para outras, que com imaginação mais brilhante, com educação mais acurada, com instrução mais vasta e liberal, tenham mais timidez do que nós (REIS, 2018, s/p. grifo meu).
\end{abstract}

Após a boa recepção do livro à época da publicação, Úrsula foi silenciado, apagado e, apesar da sua temática precursora e de sua qualidade estética, nunca foi inserido no cânone literário brasileiro, tendo sido resgatado quase um século depois, já na década de 1970. Neste contexto de "esquecimento" dos historiadores de literatura, podemos afirmar que Carolina Maria de Jesus não teve acesso à escrita de Maria Firmina dos Reis. Como teria sido se além de ler Navio Negreiro (1868), de Castro Alves, Carolina tivesse lido também Úrsula (1859), de Maria Firmina dos Reis, autora maranhense que escreveu sobre a crueldade do tráfico de pessoas sequestradas na África e trazidas à América para exploração de mão de obra?

No artigo intitulado Infecção na sentença: a escritora e a ansiedade de autoria, de Sandra Gilbert e Susan Gubar (2017), inserido no livro Traduções da cultura: perspectivas críticas feministas (1970-2010), as duas estudiosas de literatura inglesa do século XIX, 
baseadas na teoria de Harold Bloom, que encerra um modelo de história literária exclusivamente masculino e patriarcal, afirmam que os escritores homens sofriam de "ansiedade de influência". Esse conceito de "ansiedade de influência" de Bloom pressupõe que os poetas homens ao escrever devem superar seus precursores. Bloom se apoia na genealogia da psicanálise freudiana em que somente o menino pode tomar o lugar do pai, enquanto à menina resta subjugar-se à Lei do Pai e tornar-se representante da natureza e da sexualidade. Então onde se encaixaria a poeta nesse modelo de história literária?

De acordo com Sandra Gilbert e Susan Gubar (2017), as poetas mulheres sofriam de "ansiedade de autoria", que seria "um temor radical de não poder criar, de que, porque ela nunca poderá vir a ser uma 'precursora', o ato de escrever irá isolá-la ou destruí-la” (Gilbert; Gubar, 2017p. 193). O processo poético no século XIX permitia o encontro do poeta (homem) com a musa (mulher), assim, as escritoras careciam de precursoras e, muitas vezes, adotavam os precursores masculinos como sendo seus, o que poderia garantir certa autoridade, mas também transmitir falhas na experiência da própria identidade como escritora.

Transpondo a distância espacial e temporal da análise de Sandra Gilbert e Susan Gubar, podemos sustentar que no Brasil do século XIX e início do XX, tanto Maria Firmina dos Reis como Carolina Maria de Jesus não tiveram referências de poetas mulheres. Sobre Carolina sabe-se pela sua escrita e biografia, teve grande influência de Castro Alves, o poeta dos escravos, e por uma identificação queria ser conhecida como a poeta dos pobres. Resgatadas do silenciamento imposto por um pensamento sexista e patriarcal e reconhecidas pela qualidade e pelo ponto de vista diferenciado que suas obras revelam, as duas podem ser consideradas precursoras na literatura brasileira e servem de inspiração e de influência para novas escritoras.

A análise de Sandra Gilbert e Susan Gubar (2017) apontam para uma nova fase da história literária ocidental em que,

enquanto os escritores têm se sentido cada vez mais exaustos pela necessidade de revisão que a teoria da 'ansiedade de influência' de Bloom acuradamente descreve, as escritoras têm visto a si mesmas como pioneiras em uma criatividade tão intensa, que suas contrapartes masculinas provavelmente não experimentam algo análogo desde a Renascença, ou, pelo menos, desde o Filho de muitos pais; o escritor de hoje em dia se sente desesperadamente tardio. Já a escritora de hoje em dia, filha de tão poucas mães, sente que está ajudando a criar uma tradição viável que, por fim, está definitivamente, emergindo (GILBERT; GUBAR, 2017, p. 195). 
Maria Firmina dos Reis e Carolina Maria de Jesus eram órfãs de referência literária feminina no Brasil, e se praticamente não tinham acesso à escrita de outras mulheres, menos chances ainda de mulheres negras, e então tiveram que trilhar os seus próprios caminhos, em muitos aspectos reproduzindo estilos e temas dos escritores brasileiros consagrados. Embora Maria Firmina e Carolina denunciassem cada uma a seu modo os preconceitos, as hipocrisias e as violências presentes na sociedade de suas respectivas épocas, tanto no período escravocrata quanto após a "libertação" dos negros escravizados, ambas sofreram influências do discurso patriarcal em suas obras. Hoje, no entanto, compreendidas as restrições e os limites de cada uma, são tidas como referências para escritoras contemporâneas, especialmente as negras como Elizandra Souza, Jarid Arraes, Jenyffer Nascimento, Ana Maria Gonçalves e Conceição Evaristo.

\section{As reescritas e as interferências na obra de Carolina}

Várias questões de ordem editorial rondam a obra de Carolina. Diário de Bitita foi publicada primeiro na França pela Éditions Métailié, com o título de Journal de Bitita, e só sairia no Brasil quatro anos depois, em 1986, a partir da tradução do francês para o português brasileiro. Em uma pesquisa minuciosa sobre a publicação do Journal de Bitita na França e do Diário de Bitita no Brasil, Raffaella Andréa Fernandez (2014), em um artigo publicado na revista SCRIPTA, "Vários 'Prólogos' para um Journal de Bitita/Diário de Bitita ou Por que editar Carolina?", revela que

as edições brasileiras de Journal de Bitita (1982) são uma cópia do texto estabelecido e traduzido pela jornalista brasileira Clélia Pisa que, em 1972, recebeu das mãos de Carolina Maria de Jesus dois cadernos manuscritos, um com diversos poemas intitulados "Um Brasil" e outro contendo diversas narrativas autobiográficas nomeado "Um Brasil para brasileiros" (FERNANDEZ, 2014, p. 285).

De acordo com a pesquisa de Raffaella Fernandez (2014), alguns dos textos originais de Diário de Bitita estão localizados atualmente na Biblioteca Nacional no Rio de Janeiro e no Instituto Moreira Sales em São Paulo e revelam que o livro teve um prólogo escrito pela própria 
Carolina, além de sete versões mapeadas e, em seguida, cotejadas pela pesquisadora. Os originais cotejados no artigo referem-se ao capítulo do livro "A escola" e demonstram os diferentes momentos do processo criativo, apontando para a complexidade de se editar os textos de Carolina. Raffaella Fernandez conclui que as reescritas das mesmas lembranças e situações em Diário de Bitita favorecem o ofício de poeta, enquanto os acréscimos e as autocorreções nos originais convergem para o autodidatismo da trajetória de Carolina. Durante a pesquisa de doutoramento, Raffaella Fernandez entrevistou ainda Marie Métailié, da editora Métailié em Paris, a jornalista Clélia Pisa e Audálio Dantas, o "descobridor" e editor de Quarto de despejo: diário de uma favelada, e os três são unânimes em afirmar que a obra de Carolina Maria de Jesus deveria ser revisitada e publicada de forma mais genuína, "sem cortes sem reajustes ou traduções" (FERNANDEZ, 2014, p. 292), a fim de enriquecer o debate em torno da marginalidade no Brasil, em várias instâncias: cultural, literária, econômica e sociológica. Como Carolina morre em 1977 e as versões de Journal de Bitita e Diário de Bitita são publicadas postumamente, a escritora não teve acesso a nenhuma das duas publicações.

Os estudos de cunho etnográfico e histórico de Raffaella Fernandez (2014) enriqueceram e explicaram o contexto em que se deu o processo de escrita e de publicação dessa obra múltipla e polifacetada e me fizeram questionar como as interferências feitas no texto original, os acréscimos e as correções feitas pela editora francesa, a troca do título, a tradução do francês para o português, podem ter sido positivas ou negativas em relação ao texto final.

De acordo com outro estudo acerca da vida e da obra de Carolina, realizado pela pesquisadora Germana Henriques Pereira de Sousa, intitulada Carolina Maria de Jesus: o estranho diário da escritora vira lata (2012), as interferências dos editores na trajetória de Carolina foram recorrentes. Em Quarto de despejo: diário de uma favelada, Audálio Dantas também o fez ao selecionar os trechos dos vinte cadernos que continham o dia a dia de Carolina para compor o livro. No prefácio à primeira edição, em 1960, o jornalista ao apresentar Carolina Maria de Jesus como escritora afirma que participou da seleção dos manuscritos e que "foram feitos cortes, selecionados os trechos mais significativos [...] Mexi, também, na pontuação, assim como em algumas palavras cuja grafia poderia levar à incompreensão da leitura. E foi só, até a última linha" (DANTAS, 1993 apud SOUSA, 2012, p. 42). Após mais de trinta anos do lançamento de Quarto de despejo, as declarações a respeito de Carolina e de sua obra, feitas por Audálio Dantas para o biógrafo da autora, José Carlos Sebe Bom de Meihy, revelaram 
julgamentos acerca do ponto de vista da autora expresso no diário e maiores interferências editoriais, como vemos a seguir:

[...] tenho a profunda convicção, por tudo o que li sobre ela, por seu comportamento, de que, ao mesmo tempo, em que vivia aquela situação de profunda miséria, ela sempre se considerou uma pessoa acima daquele grupo do qual fazia parte. Carolina representava, de certo modo contraditoriamente - e isso para mim é muito importante dizer -, a visão do colonizador, no sentido amplo do termo, por mais paradoxal que isso pareça. Tinha a visão do branco, dos que detêm o poder. (MEIHY, 1994 apud SOUSA, 2012, p. 45)

O diário tinha uma força de expressão narrativa muito grande, enquanto a poesia era a busca de fazer rima, e terminava na maior parte das vezes em besteira [...] O que ela não tinha imaginado era um livro como Quarto de despejo (MEIHY, 1994 apud SOUSA, 2012, p. 45-46).

Sobre a vida pessoal e a obra de Carolina, Audálio Dantas faz duras críticas e chega a tomar para si a coautoria de Quarto de despejo, se não de conteúdo, pelo menos da forma, e coloca sob suspeita o contraponto entre a escritora e a favelada ou o deslocamento do ponto de vista de classe da autora, um dos elementos mais pulsantes de sua obra.

Elzira Divina Perpétua, em Traços de Carolina Maria de Jesus: gênero, recepção e tradução de Quarto de despejo, citada por Germana Sousa (2012), afirma, a partir da análise do corpus de originais de Quarto de despejo, que houve um direcionamento do editor a fim de transformar Carolina em uma personagem que representasse uma parcela miserável da população brasileira, além de uma tentativa de moldar sua personalidade para atender aos interesses do público:

[...] as modificações realizadas na transposição dos manuscritos para o livro publicado mostram que o projeto de Quarto de despejo realizou-se como um ato intencionalmente predeterminado de conferir à publicação um valor de representação coletiva da miséria e do abandono do favelado. Para cumprir esse objetivo, foi necessário que o editor adaptasse a narradora a um modelo de sujeito que convergisse para uma personagem que, além de íntegra, forte, resignada e atenta aos problemas da comunidade, fosse também submissa, passiva, sem capacidade de julgamento, sem liberdade interior - enfim, um produto e não produtora de um destino (PERPETUA, 2000 apud SOUSA, 2012, p. 43). 
Neste contexto, percebe-se o quanto a autora que se autodenominava "vira lata", marginalizada pela condição de mulher, negra e favelada, para ser publicada, teve que ceder, a contragosto, às imposições do mercado editorial, do início ao fim da carreira literária, teve que se enquadrar num papel de submissão e de mercadoria que a levou à completa desilusão com a vida literária e, provavelmente, ao seu isolamento, pois como ela mesma dizia: "não me adapto a ser teléguiada" (JESUS, 1996, p. 136).

O contexto histórico do Brasil também corroborou com o isolamento de Carolina, como podemos verificar por meio da pesquisa de Germana Sousa, na qual a estudiosa afirma que a escrita poética de Carolina é forjada na tentativa de emergir de uma camada subalterna à elite, revelando uma linguagem fraturada e um deslocamento de ponto de vista de classe. No seu primeiro livro, Quarto de despejo: diário de uma favelada (1960), esse deslocamento faz um contraponto à política de modernização do presidente republicano Juscelino Kubitschek, porém, com o Golpe Militar de 1964 e a ditadura implantada no Brasil, sua obra passa a ser silenciada e apagada da cena literária por sua crítica social contundente não atender ao padrão proposto pelos militares: "Carolina de Jesus problematiza a literatura e, por seu intermédio, também a sociedade, ao apresentar a tensão entre o alto e o baixo, o lixo e o livro, a figura do escritor e a favelada" (SOUSA, 2012, p. 20).

Paradoxalmente, no que se refere à forma e à linguagem, Germana Sousa (2012) afirma que os textos de Carolina têm traços de uma cultura dominante assimilada, sua escrita é repleta de anacronismo literário, de preciosismo, de imitação do estilo romântico, inspirada nos poetas Casimiro de Abreu e Castro Alves, justamente num período em que a literatura brasileira já tinha passado pela Semana de Arte Moderna, pelo romance de 30 e tentava se desvencilhar do academicismo e do tradicionalismo.

Com a vida conturbada depois do sucesso transitório de Quarto de despejo, em 1960, e do silenciamento imposto a Carolina, que, após o primeiro livro publicado, é esquecida pelas editoras e pela sociedade ávida apenas pela novidade exótica de ter uma escritora favelada, Diário de Bitita parece ter sido escrito para proporcionar uma pacificação interna à escritora e dar uma resposta ao público que a tinha devolvido ao "quarto de despejo". Ao escrever, já na idade adulta, as memórias de infância, Carolina resgata o apelido de criança, Bitita, e busca revelar que estava predestinada desde cedo a ser uma poetisa, apesar das misérias e das humilhações vividas na cidadezinha de Sacramento, em Minas Gerais: 
Minha mãe pegou-me e levou-me ao médico espírita, o senhor Eurípedes Barsanulfo. [...] Ele disse-lhe que o meu crânio não tinha espaço suficiente para alojar os miolos, que ficavam comprimidos, e eu sentia dor de cabeça. Explicou-lhe que até aos vinte e um anos eu ia viver como se estivesse sonhando, que a minha vida ia ser atabalhoada. Ela vai adorar tudo que é belo! A tua filha é poetisa; pobre Sacramento, do teu seio sai uma poetisa. E sorriu (JESUS, 2014, p. 73-74).

No entanto, apesar de acreditar-se predestinada, Carolina se denominava uma escritora "vira-lata" e se sentia uma "infiltrada" no espaço literário brasileiro. A realização do sonho de ser escritora possibilitou que ela e seus filhos saíssem da favela e fossem morar numa casa de alvenaria, porém trouxe também desilusão após ela desmascarar o lado perverso e excludente da elite cultural brasileira. Consciente de sua condição de mulher negra e ex-favelada, a autora escreve em $\mathrm{Meu}$ estranho diário: "quando infiltrei na literatura sonhava só com a ventura" (JESUS, 1996, p. 151).

\section{A escrita autobiográfica de Carolina}

Em Diário de Bitita, apesar do título do livro conter a palavra diário, o formato corresponde a uma narrativa autobiográfica, ou seja, a referência ao gênero íntimo não define a tipologia textual, mas pode ter sido por parte da editora uma tentativa de chamar a atenção do público e recuperar o sucesso de Quarto de despejo: diário de uma favelada.

Philipe Lejeune, em O pacto autobiográfico: de Rousseau à internet (2008), formula possíveis teorias sobre autobiografias, biografias, diários, romances autobiográficos, conjecturando a respeito da existência real ou verificável daquele que escreve e daquilo sobre o que se escreve. Porém, devido à multiplicidade de escritos autobiográficos e à amplidão de formas de leituras, a construção teórica do pacto deixa algumas lacunas e revela-se, por vezes, insuficiente.

Para Lejeune (2008), se não houver pacto, não há autobiografia, por isso, quando o nome do narrador-personagem difere do nome do autor, não é possível haver identificação. Sendo 
assim, a assinatura do nome do autor na capa do livro sustentaria o pacto autobiográfico. Germana Sousa (2012) resolve essa questão teórica ao explicar que:

Diário de Bitita é, ao mesmo tempo, uma ficcionalização da escritora Carolina Maria de Jesus e a complementação, pela narrativa da infância, da personagem Carolina de Jesus. O trajeto da autora, de Bitita a Carolina Maria de Jesus, conclui e sela o pacto autobiográfico entre autor e leitor. (SOUSA, 2012, p. 106)

Lejeune (2008) ressalta que é importante o leitor saber e aceitar que o texto é autobiográfico no ato da leitura, selando dessa forma o pacto entre quem escreve e quem lê o texto. O trecho extraído do livro que permitiu que as editoras francesas utilizassem journal no título, termo que corresponde a diário, já que no original de Carolina o título era "Um Brasil para brasileiros", foi o seguinte:

- A senhora está ficando mocinha, tem que aprender a ler e escrever, e não vai ter tempo disponível para mamar porque necessita preparar as lições. Eu gosto de ser obedecida. Está ouvindo-me, dona Carolina Maria de Jesus!

Fiquei furiosa e respondi com insolência:

- O meu nome é Bitita.

- O teu nome é Carolina Maria de Jesus.

Era a primeira vez que eu ouvia pronunciar o meu nome. (JESUS, 2012, p.127)

A escolha do título Diário de Bitita conduz o leitor a crer que se trata de uma escrita íntima, diarística, de esfera privada, porém essa ideia lançada pelo título não condiz com a intenção da escritora de divulgação pública de sua história de vida e com o formato da autobiografia. Esse detalhe do título revela que o texto de Carolina teve interferências que possivelmente visavam alcançar o sucesso de vendas mais do que a coerência da obra. No entanto, temos que reconhecer que sem os editores, tanto Audálio Dantas como Marie Métailié, provavelmente Carolina nunca tivesse sido publicada e não teríamos a chance de conhecer seu diário ou sua autobiografia. 


\section{Bitita: escrava ou liberta?}

Diário de Bitita é repleto de histórias da escravidão no Brasil e também de lembranças do período logo após a "libertação" dos escravos. Carolina escancara o completo abandono dessa parcela da população brasileira e a continuidade da exploração a que os negros eram submetidos, pois o país não teve uma política social que auxiliasse na transição da escravatura à liberdade, que acolhesse ou apoiasse os negros. A autora chega a dizer que para ela "a escravidão havia apenas amainado um pouquinho" (JESUS, 2014, p. 160). Carolina deixa evidente no seu texto qual era a realidade da situação da população negra, de como eram humilhados, quanto mais escura a cor da pele, mais inferiores eram considerados pelos brancos e pelos próprios negros. Em diversos momentos percebe-se a desvalorização do corpo negro, em especial das mulheres, como quando Carolina transcreve um diálogo entre dois homens: “eu dormi com uma pretinha, e dei cinco mil-réis para ela" e o outro responde “- eu dei dez para a branca" (JESUS, 2014, p. 49). A classificação de pessoas por raça e a atribuição de valor inferior ao corpo da mulher negra seria, portanto, uma forma de perpetuação da escravidão, ainda mais acentuada para a parcela feminina dessa população.

As memórias de Carolina adulta trazem à tona passagens da vida de Bitita em detalhes, contam as histórias dos seus antepassados, da sua origem de filha bastarda, da ida à escola por apenas dois anos, questionam a diferenciação entre negros, mulatos e brancos, expõem as explorações nos trabalhos domésticos em casas de brancos, apontam os privilégios dos homens em relação às mulheres na sociedade, relatam as prisões injustas das quais foi vítima, denunciam o projeto de branqueamento da raça, narram as andanças em busca de cura para suas feridas, as humilhações que sofreu pedindo esmolas. O livro é finalizado no momento da sua chegada em São Paulo em busca de trabalho digno e de uma vida melhor, cheia de esperanças: "Quem sabe ia conseguir meios para comprar uma casinha e viver o resto de meus dias com tranquilidade..." (JESUS, 2014, p. 206). Diário de Bitita reflete as consequências do período da escravidão, parte repulsiva da nossa história, na vida daquela menina negra e pobre do início do século XX no Brasil.

Um dos temas abordados por Carolina em Diário de Bitita que tem uma forte relação com a herança do período da escravidão no Brasil é o do branqueamento da raça e da miscigenação. Em diversos momentos do texto ela faz a separação e a marcação das pessoas de acordo com a cor da pele: “os brancos não iam presos" (JESUS, 2014, p. 46), "ter uma pele 
branca era um escudo, um salvo-conduto" (JESUS, 2014, p. 55), "aquela filha branca era o orgulho da tia Ana. Era a predileta" (JESUS, 2014, p. 75), "a Jerônima fugiu com um homem branco. Porque tinha nojo de ter uma sogra preta" (JESUS, 2014, p. 80), “o meu irmão era o predileto. Eu pensava: 'Ela trata-o com todo carinho, porque ele é mulato. E eu sou negrinha" (JESUS, 2014, p. 83) e "o soldado que matou o nortista era branco. O delegado era branco. E eu fiquei com medo dos brancos e olhei a minha pele preta" (JESUS, 2014, p. 116).

O processo de apagamento da memória da escravidão no Brasil é tão evidente e institucionalizado que o próprio Hino à Proclamação da República, com letra de Medeiros e Albuquerque, de 1890, menos de dois anos após a abolição da escravatura no Brasil, que ocorreu em 1888, diz em um dos seus trechos que:

\author{
Nós nem cremos que escravos outrora \\ Tenha havido em tão nobre País \\ Hoje o rubro lampejo da aurora \\ Acha irmãos, não tiranos hostis \\ Somos todos iguais! Ao futuro \\ Saberemos, unidos, levar \\ Nosso augusto estandarte que, puro \\ Brilha, ovante, da Pátria no altar!
}

"Nós nem cremos que escravos outrora tenha havido em tão nobre País" e "acha irmãos, não tiranos hostis" são exemplos de tentativas de minimizar os efeitos da escravidão, de dizer que os negros eram aceitos como brasileiros. A parte que diz "saberemos, unidos, levar nosso augusto estandarte" anunciava, tão logo assinada e promulgada a Lei Áurea, o projeto de naturalização das diferenças raciais. Unidos pode ser uma referência à mestiçagem e ao branqueamento da raça, política adotada no Brasil naquele período.

Em Nem preto nem branco, muito pelo contrário: cor e raça na sociedade brasileira (2012), Lilia Moritz Schwarcz apresenta um conjunto de fatos históricos determinantes para a questão racial no Brasil. De acordo com a pesquisadora o conceito de raça no caso brasileiro é construído histórica e socialmente, não sendo possível estabelecê-lo por modelos de descendência biológica: 
Raça é, pois, uma categoria classificatória que deve ser compreendida como uma construção local, histórica e cultural, que tanto pertence à ordem das representações sociais - assim como são as fantasias, mitos e ideologias como exerce influência real no mundo, por meio da produção e reprodução de identidades coletivas e de hierarquias sociais politicamente poderosas (SCHWARCZ, 2012, s.p.)

Segundo Lilia Schwarcz (2012), o Brasil surgia como um grande laboratório racial no período pós "libertação" da escravatura e que as peculiaridades, mais colorações do que raça, geraram um racismo à brasileira, que admite até os dias de hoje a discriminação na esfera privada. Na passagem do século XIX para o XX os discursos dominantes defendiam uma política de branqueamento da população nacional e projetavam uma imagem de democracia racial, de valorização dos mestiços. A literatura brasileira, como a pesquisadora revela em suas análises, tem indícios desse período de formação da cultura nacional e cita como exemplo Euclides da Cunha em Os sertões, de 1902, que oscilava entre considerar o mestiço um forte ou um desequilibrado, porém julgando a mestiçagem como um retrocesso.

Uma das leituras de Lilia Schwarcz sobre Casa-grande e senzala, publicado em 1933 por Gilberto Freyre, cuja questão central é o encontro intercultural nos trópicos, mostra como se deu a invenção do mito da democracia racial. Em sua obra, Gilberto Freyre introduz os estudos culturalistas como solução para o encontro das "três raças" que compunham o povo brasileiro, apresenta uma versão otimista da mistura de raças no Brasil e expõe um modelo de sociedade multirracial. O antropólogo mantém intocados os conceitos de superioridade e de inferioridade das raças em relação às práticas sociais, além de muitas vezes deixar transparecer que a escravidão no Brasil foi um mal necessário. Ao destacar em sua obra a intimidade da casa-grande e da senzala, onde viviam os senhores e os escravos domésticos, omite a vida mais dura dos escravos do campo que, pelas péssimas condições de sobrevivência, envelheciam e morriam precocemente.

Em Diário de Bitita Carolina narra uma experiência vivida na pele que representa exatamente essa política de branqueamento da nação, na qual a raça é associada aos mecanismos de construção da República no Brasil e à criação de uma imagem nacional. Uma de suas várias patroas brancas, além de explorar sua força de trabalho infantil, julga sua aparência e promete deixá-la com a fisionomia de uma menina branca: 
Minha mãe respondia com polidez. Minha mãe era do ventre livre e dizia que os brancos é que são os donos do mundo. Ela aprendeu a dizer aos brancos apenas:

- Sim, senhora, sim, senhor.

Quando chegou a minha vez, a fazendeira examinou-me minuciosamente com o olhar. Como se eu estivesse à venda, dizendo que eu era uma negrinha esperta. [...]

A dona Maria Cândida pediu à minha mãe para eu ir todas as manhãs auxiliála na limpeza da casa. Minha mãe consentiu. [...]

- Sabe, Carolina, você vem trabalhar para mim, e quando eu for a Uberaba eu compro um vestido novo para você, vou comprar um remédio para você ficar branca e arranjar um outro remédio para o seu cabelo ficar escorrido. Depois vou arranjar um doutor para afilar o seu nariz.

Ela permaneceu dois dias fora. Quando regressou, encontrou-me de plantão à sua espera, mas fiquei decepcionada. Ela não trazia pacotes. Então ela enganou-me. Pensei nos seis meses que trabalhei para ela sem receber um tostão. Minha mãe me dizia que o protesto ainda não estava ao dispor dos pretos. Chorei. (JESUS, 2014, p. 136-137)

Esse trecho do Diário de Bitita pode ser considerado um resumo da política de branqueamento da população. Carolina condensa e revela todo o preconceito contra os negros e o racismo enraizado na nossa cultura desde os quase 400 anos de escravidão sofridos no Brasil. Os discursos eugenistas vigentes, inclusive baseados em visões cientificistas, apoiavam a esterilização dessa população negra marginalizada.

\section{CONSIDERAÇÕES FINAIS}

As impressões da análise sobre o isolamento imposto a Carolina Maria de Jesus, as diversas formas de intervenção em sua escrita e até a interferência para moldar uma imagem de escritora negra e favelada como submissa e, por vezes, incapaz, que atendesse a sociedade hegemônica brasileira, estão intrinsecamente relacionadas ao preconceito e ao racismo. Porém mesmo com tantas adversidades, a trajetória de Carolina como escritora abriu caminhos para 
outras mulheres negras. Essas mulheres estão ainda hoje superando desafios na cena literária brasileira, mas não são mais órfãs de referências.

A diferença entre Carolina e as novas escritoras é que para enfrentar os desafios de hoje em dia elas estão acompanhadas, existe uma rede de apoio e uma militância consolidada com bases fortes que se inspira em mulheres resistentes como ela. É o caso da ativista estadunidense pelos direitos das mulheres negras Angela Davis (2016) que, durante visita ao Brasil, fez a seguinte declaração sobre duas mulheres brasileiras que podem ser consideradas referências de luta:

Carolina Maria de Jesus lembrou que a fome deveria nos levar a refletir sobre as crianças e sobre o futuro e muito antes que o conceito de interseccionalidade fosse utilizado pela primeira vez, Lélia Gonzalez nos conclamou a entender a complexa inter-relação entre raça, classe e gênero, mas também a compreender os nossos elos com as populações indígenas, entre os povos indígenas e negros. E essa é uma das lições que nós, nos EUA, precisamos aprender com a história do feminismo no Brasil (DAVIS, 2016, s/p.).

Em seu livro Mulheres, raça e classe (2016), Angela Davis atenta para as questões contemporâneas, propõe que a representatividade deve fugir das dicotomias e defende que a população negra, majoritariamente fora dos espaços de poder, não deve simplesmente ocupálos, mas se comprometer em romper com as lógicas opressoras. O livro gira em torno de como as estratégias das ativistas norte-americanas do século XIX e início do XX foram se apropriando de posições racistas ao assumir a supremacia da raça branca como ideologia geral da época. Porém, Davis aponta o racismo a fim de assinalar a urgência de uma aliança política transversal que se coloque como meta para uma emancipação coletiva. A ativista afirma que as diferenças de gênero, raça e classe devem permitir interligar os movimentos de lutas interseccionais e desafia negras(os) e brancas(os) a conceber ações que desatrelem valores democráticos de valores capitalistas, estes últimos que estabeleceram uma ideia de inferioridade da população negra e, em especial, da parcela feminina nos Estados Unidos (e ao redor do mundo).

No caso brasileiro, Lilia Schwarcz (2012) aponta que os projetos de branqueamento e miscigenação no Brasil no período pós "libertação" tornaram-se modelos de "igualdade" racial, ocultando a violência e a desigualdade, camuflando o racismo e tornando-o assistemático. A ideia de harmonia criada pelo mito da democracia racial perdura no imaginário coletivo ainda hoje e se impõe à própria consciência de discriminação. 
A verdade é que Carolina nunca embranqueceu, nem na infância por meio do remédio para clarear a pele e escorrer o cabelo ou a cirurgia para afilar o nariz, prometidos pela patroa branca, nem mesmo na idade adulta, pois, apesar de tentar fazer parte da elite cultural brasileira, não servia para ser "teléguiada", insubmissa e desenvolta demais num mundo que não pertencia a ela. Ao final da vida Carolina retorna às ruas como catadora: "Carolina de Jesus deixou a casa de alvenaria e voltou a catar papel em São Paulo" (Jornal do Brasil, 1966).

\section{REFERÊNCIAS}

DAVIS, Angela. Mulheres, raça e classe [recurso eletrônico]. Tradução Heci Regina Candiani. $1^{\mathrm{a}}$ ed. São Paulo: Boitempo, 2016. Paginação irregular.

FERNANDEZ, Raffaella Andréa. Vários 'Prólogos' para um Journal de Bitita/Diário de Bitita ou Por que editar Carolina? SCRIPTA, Belo Horizonte, v. 18, n. 35, p. 285-292, 2º sem. 2014.

FREYRE, Gilberto. Casa-grande e senzala: formação da família brasileira sob o regime da economia patriarcal. Rio de Janeiro: Record, 1995.

GILBERT, Sandra e GUBAR, Susan. "Infecção na sentença: a escritora e a ansiedade de autoria". In: BRANDÃO, Izabel; CAVALCANTI, Ildney; COSTA, Claudia de Lima; LIMA, Ana Cecília Acioli (Organizadoras). Traduções da cultura: perspectivas críticas feministas (1970-2010). Florianópolis: EDUFAL; Editora da UFSC; Editora Mulheres, 2017.

JESUS, Carolina Maria de. Meu estranho diário. Organizado por Robert Levine e José Carlos Bom de Meihy. São Paulo: Xamã, 1996.

JESUS, Carolina Maria de. Quarto de despejo: diário de uma favelada. São Paulo: Ática, 2007.

JESUS, Carolina Maria de. Diário de Bitita. São Paulo: SESI-SP Editora, 2014.

LEJEUNE, Philippe. O pacto autobiográfico - de Rousseau à internet. Tradução de Jovita Maria Gerheim Noronha e Maria Inês Coimbra Guedes; Organização de Jovita Maria Gerheim Noronha. Belo Horizonte: Editora UFMG, 2008.

REIS, Maria Firmina dos. Úrsula e outras obras [recurso eletrônico]. Série Prazer de Ler, n. 11 ebook. Brasília: Câmara dos Deputados, Edições Câmara, 2018. Paginação irregular.

SCHWARCZ, Lilia. Nem preto nem branco, muito pelo contrário: cor e raça na sociedade brasileira [recurso eletrônico]. São Paulo: Claro Enigma, 2012. Paginação irregular.

SOUSA, Germana Henriques Pereira de. Carolina Maria de Jesus: o estranho diário da escritora vira-lata. Vinhedo: Editora Horizonte, 2012. 